Making a Connection: School Engagement of Young People In Care

Authors:

Clare Tilbury, Peter Creed, Nicholas Buys, Jennifer Osmond, and Meegan Crawford

Affiliation: Griffith University, Queensland, Australia

Contact: $\quad$ Clare Tilbury

School of Human Services and Social Work

Griffith University, Logan campus

University Drive

MEADOWBROOK Q 4131 AUSTRALIA

Email: c.tilbury@griffith.edu.au

Telephone: + 61733821406

Facsimile: +61 733821210

Acknowledgements: 
This study was supported by the Australian Research Council; the Department of Communities, Child Safety and Disability; and Education Queensland.

\title{
Making a Connection: School Engagement of Young People In Care
}

\begin{abstract}
Intervention to improve educational attainment for children in out-of-home care is increasingly being recognised as important for their wellbeing and future opportunities. The paper reports on a mixed method study of the school engagement, or connectedness, of young people in care. The study comprised a survey of 202 young people in care in Queensland, Australia and a matched comparison group of young people not in care, plus interviews with a subset of 65 young people in care who were surveyed. Both the school environment and perceived levels of support influenced school engagement, with those who were assisted by carers and caseworkers more likely to be positively connected with school. These young people perceived education as a pathway to achieving work and life goals. The findings suggest that active and focused attention on young people’s school engagement should be part of case planning and monitoring as it offers an additional strategy for improving their educational experience.
\end{abstract}

Keywords: school engagement; out-of-home care; matched sample 


\section{Introduction}

This paper focuses on the school engagement of young people in out-of-home care. It draws on a mixed methods study of the school to work transition of young people in care, and reports specifically on factors that are important for school engagement and connectedness. It is well established that it is vital for children in out-of-home care to experience stability, permanency, and the opportunity to receive assistance for dealing with trauma and other impacts of maltreatment. As part of promoting their wellbeing, the importance of children having quality educational experiences is also recognized. However, research to date has shown that children in out-of-home care are at risk of a range of unfavourable educational outcomes, such as grade repetition, missing school, suspension and expulsion, low grades, non-completion, not progressing to tertiary or other forms of post-secondary education, and generally not faring well at school (Cashmore, Paxman, \& Townsend, 2007; Ferguson \& Wolkow, 2012; Stone, 2007; Trout, Hagaman, Casey, Reid, \& Epstein, 2008).

The literature proposes a range of explanations for why children in care may not perform as well as their peers. Children may bring to out-of-home care a range of education-related difficulties due to their family circumstances, social disadvantage, poverty, and being raised in environments where education was not supported (Berridge, 2012; Flynn, Paquet, \& Marquis, 2010; Harker, Dobel-Ober, Akhurst, Berridge, \& Sinclair, 2004; Stone, 2007). Further, children in care have experienced abuse or neglect, which can have damaging effects on social, psychological, and behavioural functioning, as well as on academic performance (Frederick \& Goddard, 2010). For some children, this means that when they are at school they can be disruptive, with difficult externalising behaviours, or conversely, be withdrawn and have 
problems with attention, concentration, and participation (Altshuler, 2003; Downey, 2007). In addition, some children in care may have learning problems across a range of areas such as reading, writing, and mathematics (Iversen, Hetland, Havik, \& Stormark, 2010).

Factors in the care system have also been identified as contributing to why children in care may experience educational difficulties. It is not uncommon for children to have a number of placement changes. A placement change can lead to a school change, and loss of friends and supportive teachers (O’Sullivan \& Westerman, 2007; Trout et al., 2008). It may also cause a lack of continuity in curricula, which can lead to children missing particular concepts that can contribute to them falling behind (Trout et al., 2008). Being in care can be synonymous with other requirements that can cause educational disruption, such as attending specialist appointments or participating in contact visits with parents (Working Group on Education for Children and Young People in Out-of-Home Care in Queensland, 2011). Children in care may not have anyone who offers them assistance with homework, encouragement, advocacy, and the cultivation of pro-educational values (Allen \& Vacca, 2010; Zetlin, Weinberg, \& Kimm, 2004). System issues, such as ineffective interagency collaboration and monitoring of in-care children's educational progress, may also pose barriers to improving educational attainment (Altshuler, 2003; Ferguson \& Wolkow, 2012). Stereotypes, beliefs, and expectations of professionals may adversely influence children's educational aspirations, if, for example, teachers, social workers and carers do not expect them to do well because of their care history and accept low achievement as the norm (Harker et al., 2004; Martin \& Jackson, 2002). These attitudes may directly or indirectly be communicated to children, which can influence their aspirations, sense of self efficacy, and educational competence (Elliott, 2002). Supportive, encouraging adults and 
processes that celebrate progress and achievements can be critical for the educational success of children in care (Harker et al., 2004).

Young people transitioning from care may also face difficulties in progressing to further education because they may not have the benefit of a supportive, encouraging family, a stable home, and the financial security or backing that young people in the non-care population may enjoy (Driscoll, 2011; Kirk \& Day, 2011). Their attention might be on establishing a place to live and securing an income (Dworsky, 2010). Young people who are not able to achieve basic educational milestones can be at risk of numerous unfavourable outcomes affecting all facets of their life (Trout et al., 2008). For instance, in most countries, completion of secondary school is a basic requirement for entry into the labour market. Lack of employment or under-employment can lead to a domino effect of adverse outcomes: financial hardship, feelings of unworthiness, health and mental health problems, relationship difficulties, alcohol and substance abuse, and offending (Ferguson \& Wolkow, 2012; Forsman \& Vinnerljunga, 2012; Wise et al., 2010; Zetlin \& Weinberg, 2004). Education can and does affect all aspects of a young person’s wellbeing in both the short and long-term (Trout et al., 2008).

Participating in education for children is not just about utilitarian outcomes such as grades, certificates, university entrance, and jobs. Education is an experience, an integral part of daily life, and a critical factor in facilitating positive child to adult development. Children should be able to enjoy school even if their results are not strong. Schooling provides children with the opportunity to develop socially through engagement in activities, working in groups, having fun at playtime, excursions and camps, forming and establishing friendships, and developing a sense of school belonging and pride (Gilligan, 1998). It also plays an important social justice role in 
developing young people as citizens who are able to contribute to society (Labaree, 1997). School and significant staff can perform multiple roles in a child and family’s life, such as supporter, protector, confidant, confidence builder, and resource (Gilligan, 1998). The regularity and everydayness of school can be therapeutically beneficial for children who have been harmed (Ferguson \& Wolkow, 2012; Gilligan, 1998). Teachers can make a fundamental difference to children as caring and supportive adults. Such quality relationships can offset less than ideal other adult relationships children may have (Galbo, cited in Gilligan, 1998). These positive relationships can contribute to enhancing children's engagement in schooling (Allen \& Vacca, 2010; Blome, 1997; Fullarton, 2002; Scherr, 2007; Thomson, 2005).

Given that children in out-of-home care are an at-risk group for not reaching high levels of achievement, their engagement at school is worthy of critical consideration. By school engagement we are referring to their affinity with the school and learning environment, social connectedness with teachers and other students, and participation in other curricular and cocurricular aspects of the school. The construct of school engagement is variously defined in the literature, referred to by terms such as school connectedness, school bonding, and school attachment (Libbey, 2004). Consistent themes in measures of school connectedness and engagement identified by Libbey are the student's sense of being a part of school, a positive attitude toward school, level of teacher supportiveness and caring, presence of friends in school, motivation to learn and do well in school, belief in school rules, and participation in extracurricular activities. Specifying the concept further, Fredricks et al. (2004) proposed three components of school engagement: behavioural, emotional, and cognitive. The behavioural component refers to actions such as rule and classroom compliance, engaging in learning 
activities with persistence and effort, and participating in and contributing to social and academic opportunities within the school environment. It encompasses the conduct and behavioural aspects of learning (Fredricks et al., 2004). Emotional engagement focuses on the student's stance or attitude, and the her or his perception of staff, peers, and the learning setting. Both favourable and unfavourable reactions and appraisals may result in a range of emotions such as like, dislike, interest, anxiety, and excitement. Cognitive engagement refers to how much a student is willing to invest or contribute to the acquisition and mastery of learning tasks, including personal motivation, tenacity, and self-management. Engagement is associated with many positive academic outcomes, including achievement and persistence in school (Fredricks et al., 2004). Although there is a growing body of research which establishes that children in out-of- home care do not do as well educationally compared to children in the non-care population (Berlin, Vinnerljung, \& Hjern, 2011; Dill, Flynn, Hollingshead, \& Fernandes, 2012; Kirk \& Day, 2011; Trout et al. 2008), and research which makes recommendations about the interventions and changes in systems that may be beneficial (Driscoll, 2011; Forsmana \& Vinnerljunga, 2012; Harker et al., 2004; Martin \& Jackson, 2002), there is little research that has examined the school engagement of children in care. The purpose of this paper is to explore the behavioural, emotional and cognitive school engagement of young people in care compared with those not-incare, and in doing so, to provide guidance about enhancing school engagement through various education and care system interventions.

\section{Method}

The data are drawn from a larger study which examined the school to work transition of young people in care in Queensland, Australia. To date, we have reported on the career 
development of this group (Creed, Tilbury, Buys \& Crawford, 2011). This paper focuses specifically on findings regarding the school engagement of the young people involved.

\section{Participants}

Three sources of data inform this study: (a) survey results from 202 young people in outof-home care (predominantly family-based care with foster or kinship carers), (b) survey data from a matched sample of 202 young people not in out-of-home care, and (c) interviews with 65 children in care. The survey was posted initially to 1450 in-care children, who represented all children aged 13 years and over on care and protection orders in Queensland at the time of the study. There were 202 surveys used for data analysis (from 265 returns, 63 were discarded if the young person had left school or if there was substantial missing data). The average age of the 202 in-care participants was 15.2 years $(S D=1.3$ years; range $=12.9$ to 18.2 years $)$ and included 117 girls (58\%) and 85 boys. We also surveyed 378 children who were not in the care of the State, who were used to form a matched cohort comparison group (Farruggia, Greenberger, Chen, \& Heckhausen, 2006). The 202 not-in-care participants did not differ from the in-care group on gender composition, age, or self-reported school achievement. They may have differed on other variables, such as socio-economic status and age of carers. All in-care young people who returned a survey were invited to participate in an interview regarding their experiences. Sixty-five children agreed to participate (response rate $=24.5 \%$ ) in the interview. There were 43 girls and 22 boys (age range 14 to 18.2 years) interviewed.

\section{Procedure}

The data were collected with approval from the authors' human research ethics committee. The surveys were posted to the in-care participants, and distributed by at schools to 
the not-in-care participants. Those who completed a survey had their names placed in a draw to win prizes; those who were interviewed received a small monetary payment for their effort. The interviews were conducted face-to-face at the home of the young person, or by telephone for those in the non-metropolitan area, by a trained and experienced interviewer. Interviews generally took 40-50 minutes, were audio recorded, and transcribed.

\section{Survey materials}

Both the in-care and not-in-care young people completed scales and items measuring school engagement, school aspirations, value of schooling, school stability, and school supports. The in-care young people completed additional questions about the supports from their foster carers, supports from their caseworker, and the length of time they were in-care.

School engagement. This was assessed using a 10-item scale formulated by the National Center for School Engagement (Finlay \& NCSE, 2006). The measure is based on the three three types of engagement in the Fredricks et al. (2004) model: behavioural engagement, cognitive engagement, and emotional engagement. Students responded to items such as, "I enjoy the work I do in class”, using a 5-point Likert scale. The NCSE reported internal reliability coefficients ranging from .88 to .90 for a slightly longer scale (we deleted six items that did not apply our study; e.g., "When I first walked into my school I thought it was: Good/Bad”), and validity evidence based on convergent evidence with variables such as school achievement and attendance. Using exploratory factor analysis, we identified a single factor that accounted for $63 \%$ of the variance and contained factor loadings that ranged from .65 to .83 ; alpha $=.93$.

Educational aspirations. We asked all students to indicate (a) "What is the highest level of education you expect to complete?”, and (b) “What is the highest level of education your 
parents would like you to complete?”. For the in-care students only, we asked them to indicate (c) "What is the highest level of education your foster carers would like you to complete?”. All three questions were answered using seven options, which ranged from Year 10 to university.

Schooling role models. We asked all students about the school achievements of their parents and carers. All students were asked to indicate either Yes or No to the questions: (a) "Has anyone in your family studied at university?”, and (b) "Has anyone in your family studied at technical college / another college / or done an apprenticeship?”; in-care participants only were asked (c) “Have any of your current carers studied at university?”, and (d) "Have any of your current carers studied at technical college / another college / or done an apprenticeship?”.

Value of schooling. We asked all participants to indicate the value of completing their high school education: "Staying at school until year 12 would ... have no effect on me getting a job / might improve my chances of getting a job / will greatly improve my chances of getting a job”.

School stability. We used a single item that asked, "How often have you moved schools since starting in year 8?”, using a 3-point response format that ranged from Hardly at all (0-1 times) to Many times (more than 5 times).

School supports. We asked all participants about parents: (a) "How involved are your parents in your studies at school?”; and (b) asked in-care participants about carers, "How involved are your foster carers in your studies at school?”. Participants answered on a 4-point response format that ranged from (1) Not much involved to (4) A great deal involved. We asked all participants about their friends, (c) “How many friends do you have at school?”, and their friends' relationship with their school, (d) "How many of your friends like attending school?”, 
and (e) "How many of your friends intend to complete year 12?” (both with four options ranging from Not many to All).

In-care institutional support. In-care young people only were asked, (a) “How long have you been in care (in years and months)?”, (b) “How often do you have contact with your caseworker (Weekly/Monthly/6 Monthly/Yearly or less)?”, and (c) “How helpful is your caseworker (4-point response format ranging from Not helpful to Very helpful)?”

\section{Interview protocol}

The interviews were conducted in order to obtain a greater depth of understanding about the processes and factors considered relevant to the education and future work of young people in care. Young people were asked about their ideas, attitudes, and activities in relation to their education and future work goals, the factors and people influencing them in making decisions in these areas, and generally about what they perceived as hindering or helping them in transitioning from school to work. In particular, they were asked to describe their school experiences. Prompts included what they liked and did not like about school, issues of behaviour, access to resources, and the things that pleased or concerned them regarding their performance at school.

\section{Results}

\section{In-care/Not-in-care Group Differences}

We used a MANOVA and chi-square analyses to test for differences between the two groups. For the MANOVA, school variables that were completed by all participants (i.e., school engagement, school aspirations for self and parents, school stability, school support from parents, and peer support) were included as dependent variables, and group and gender were included as 
fixed factors. Gender was included to determine if any differences were moderated by this variable. There was a significant multivariate effect for group, $F(8,374)=12.26, p<.001$, but not for gender or the interaction between group and gender. Using a more stringent p-value (Bonferroni correction of .006; i.e., .05 $\div$ 8), the in-care group reported more school engagement, but lower aspirations for themselves, saw their parents as having lower aspirations for them, received less support from parents with their studies, and reported less school stability (all pvalues < .001). See Table 1 for descriptive statistics. We used chi-square analyses to test for differences in frequencies between the two groups on school role models (family at university, family at college). While there was no difference reported in relation to having family who studied at university ( $p=.06$ ), the in-care group were more likely to report family having attended college, $\chi^{2}(1)=10.02, p=.002$.

\section{Insert Table 1 here}

\section{Correlates of School Engagement}

We conducted two hierarchical multiple regression analyses to test for the correlates of school engagement separately for the two groups. In both analyses, school engagement was the outcome variable, and predictor variables were included if they had significant, bivariate correlations with an outcome variable. See Table 2 for bivariate correlations. For the analysis with the in-care group, school achievement was controlled for at Step 1. School aspirations of parents, school stability, parent support with studies, friends who like school, friends who intend to finish year 12, and having family at college were included at Step 2. Finally, the specific incare related variables of carer support with studies and how helpful was the caseworker were 
included at Step 3. At Step 1, school achievement accounted for $4.6 \%$ of the variance in school engagement, $F(1,180)=8.78, p=.003$. At Step 2 , support from parents with studies $\left(\beta=.16, s r^{2}\right.$ $=2.5 \%)$, having friends who liked school $\left(\beta=.17, s r^{2}=1.9 \%\right)$, and having family at college ( $\beta=$ -.17, $\left.s r^{2}=2.9 \%\right)$ accounted for an additional $14.8 \%$ of the variance, $F(6,174)=5.34, p<.001$. At Step 3, the in-care questions of carer support with studies $\left(\beta=.23, s r^{2}=4.5 \%\right)$ and caseworker helpfulness ( $\beta=.18, s r^{2}=2.9 \%$ ) accounted for an additional $8.8 \%$ in school engagement, $F(2,172)=10.55, p<.001$. At this final Step, in-care young people who reported receiving more support with their studies from carers, having more helpful caseworkers, and having fewer family attending college, also reported higher school engagement, over and above their reported school achievement level, which also was significant, $F(9,172)=7.53, p<.001$. Summary data for this analysis are reported in Table 3.

Insert Table 2 here

For the not-in-care group, school achievement was controlled for at Step 1. School aspirations of self, parent support with studies, friends who like school, and friends who intend to finish year 12 were included at Step 2. At Step 1, school achievement accounted for $11.1 \%$ of the variance in school engagement, $F(1,196)=25.67, p<.001$. At Step 2 , support from parents with studies $\left(\beta=.27, s r^{2}=6.6 \%\right)$ and having friends who liked school $\left(\beta=.19, s r^{2}=3.2 \%\right)$ accounted for an additional $15.6 \%$ of the variance, $F(4,192)=10.31, p<.001$. At this final Step, not-incare young people who reported receiving more support with the studies from parents and having more friends who liked school, also reported higher school engagement, over and above their 
reported school achievement level, which also was significant, $F(5,192)=14.36, p<.001$. See Table 3 for summary data for this analysis.

Insert Table 3 here

Interviews

The focus of the qualitative analysis was on participants' experience and perceptions of school. A close reading of the transcripts established broad themes categorised as either positive or negative schooling experiences. From this, the data were interrogated deductively using a framework of cognitive, behavioural, and emotional engagement. Data were grouped into these three themes and comparisons were made between excerpts in order to highlight commonalities, differences, and issues. In the following section, examples are provided regarding the different dimensions of engagement as thematically evident in the participants' accounts. The concepts do overlap, and in some instances statements could be characterised as a combination of the three dimensions, rather than just one.

For most of the young people who felt positive about school it was evident that they were motivated to achieve and willing to invest effort, indicating cognitive engagement. They felt they were on a clear pathway to post-secondary education and qualifications (e.g., technical certificates or diplomas), university, or a job. Some of these young people had received assistance to map out and progress their ideas for future careers in a planned and achievable manner by school staff and other supportive adults. For example, some were undertaking their senior subjects concurrently with technical courses, which would result in either a direct progression to a technical college upon school completion or the acquisition of a qualification. The progression from a technical qualification meant for some that this would bring them closer 
to their ultimate career aspiration: "I'm in the middle of a childcare traineeship ... I'm not going to specifically go into childcare, but it will still help with being a primary school [teacher]" (\#20072).

Many young people regarded their own efforts and beliefs as central to their possible success: “If I set my mind to it I can do it” (\#20182); “[to achieve academically] you need to believe that you can do it” (\#20180). A number of the young people wanted to succeed in order to be different to their parents. For example, they wanted to get a good job and not be in receipt of government benefits: "Because my mum and dad dropped out of school, it's something that I don't want” (\#30044); “[I want to be] ... not getting on drugs and not going to jail and to have a job and not smoke” (\#20199). Gaining an education was something they could do to increase their chances of positive life outcomes, even if they did not like school, because: “[school is] boring ... You've gotta learn, to like, get a better job ... if you don't want to learn, you're going to end up a trolley pusher” (\#20044). But many young people reported success with some aspect of schooling. Examples were high grades in particular subjects, being in the highest class for a subject, being good at art and drama, reporting that they found schoolwork easy or easier than anticipated, being fit, managing a part-time job and school demands well, or being good at football. These young people felt good about what they were achieving and how they were managing school.

Many participants said they got on with their work and behaved well at school, exhibiting behavioural engagement: “When I'm in class, I sit down and, like, I do my work and like, I don't muck around” (\#20182). However, there were a small number of young people who were not attentive or interested, also reflecting the behavioural dimension of engagement. School seemed 
to be fraught with difficulties and not perceived positively. Several had been suspended, expelled or involved in fights, truancy, and disruptive behaviour in class and towards teachers: "not doing my work, not going to school, back chatting teachers” (\#20002). Other difficulties reported were that school was boring or not challenging enough: "School’s boring sometimes” (\#20212), or conversely too difficult: "The journey through school was very hard for someone like me since I've got ADHD and Aspergers" (\#30046).

Many participants expressed positive views about school, liking the work as well as teachers, indicating emotional engagement: “overall I like learning new things. I'm very keen in having work and I love writing stuff and I love getting stuck in to an assignment and getting it done and you feel good when you've done something and you get a good mark for it, you just feel proud and stuff' (\#20094). Timely and positive support from teachers was clearly one of the most important factors which affected participants' level of emotional engagement at school. The impact and influence of positive teachers was quite compelling and made a difference to many of these young people. "[Teachers are] friendly, when you need help with assignments, they help you (\#20067)"; "the good thing about him is that...he's not like always working you to the bone ... he like mucks around with you sometimes”(\#20182). A number of the young people also expressed that they had developed good relationships with particular teachers, and from this, feelings of trust. One young person was quite aware of the value of this if a school change was to occur: "Some of the teachers, I have gained trust with them and everything. If I got to another school I've got to work all that up again.... I can joke with them and everything and they know my weak points” (\#20199). 
Flexible and supportive school processes and structures were also appreciated by some students. Information sessions on particular issues, courses that facilitated work readiness, opportunity for students to provide feedback to school staff on what they needed, tutorial assistance, and “people [who are]... there to support you no matter what happens” (\#20180). Another reason why some participants were emotionally engaged with schooling was that the school experience was a source of enjoyment: "I think it's the only escape that I have from everything, because even though school is for work, school is also for me seeing my friends" (\#20061). For many of these young people, they had experienced considerable disruption and trauma during their childhood. For some, this resulted in numerous placement, school, and peer changes, and learning to adapt to new and different environments. School was perceived as somewhere safe, constant, reliable, and removed from aspects of their situation they did not like. These young people felt positive about school: "School was like, just everything - I hated living at home, I never wanted to be off sick from school” (\#20186); “[school] I like it better than home... you have something to do" (\#20180); “School is basically really good. I'm really stable at the moment because I've been there for three years, so the longest school I've been to" (\#20166).

In contrast, those who were less positive about school expressed difficulties with the academic requirements of school, as well as challenges with teachers and peers. Teachers were perceived at times as unsupportive, unhelpful, and unfair. “I got picked on by other kids and sometimes teachers... like victimizing us...says things like, foster kids think they can get away with everything, like not having a uniform” (\#20150); “I found that in my math classes the teachers were running to everyone else but the one who needed help, which was me” (\#20147). 
Other students were also a source of difficulty: “They’d make smart remarks like 'at least my Mum loves me’” (\#20150). Some participants reported bullying, teasing, or disruptive peers in the classroom, which affected their capacity and opportunity to learn and engage with the curriculum: “just trying to concentrate in class when you've got other students behind you acting stupid and all that... I just get sick of the distractions” (\#20200). One young person expressed that associating with peers who were involved in unproductive behaviour also had an impact: "[I was] hanging out with new people and they were all into wagging school... smoking... drugs and alcohol" (\#20045). A few of the young people felt that school was not right for them: "Because I'm in care it's sort of hard for me to fit in with most people...I get angry really easy" (\#30044); “I’m over my child life now...children go to school. So I'm trying to act like a grown up and mature so I just want to get a job” (\#30045). Personalised education plans are required for all children in care, and are meant to ensure attention to children's achievement and participation in school activities. However, few young people participated in their development, and they did not seem to be a source of assistance: "I just sat there listening, I agreed. I was allowed to agree or disagree" (\#20111). One young person did comment that he did not want to be involved: “I don't read it... I don't even want a copy, just more paper for me to put away somewhere" (\#20200).

The impact of being in care for some of the young people did influence their engagement or connectedness to school. Placement in out-of-home care did at times result in changes to school and friends. A number of the young people commented that changing placements was highly disruptive and made it difficult to grasp concepts and curriculum unique to each school. “[changing in year 8 and 9] I don't get some of the stuff that I'm supposed to know because I 
was not at one school long enough" (\#20045); "it would have been easier if I had also not moved so much during my primary school, because in primary school you learn everything you need to know for high school” (\#20152). One young person also reported that being in care was viewed negatively by others, that stereotypical beliefs were held that young people were in care because of behaviour problems; so at times she felt unfairly judged. She considered that this contributed to why she could not obtain part-time employment. Conversely, two young people commented that being in care was a positive factor in their lives. One indicated that it had made her a stronger person and capable of facing difficulties, and for the other, it was the opportunity to live in an environment free from drugs and chaos.

\section{Discussion}

In this paper, we examined a range of school engagement variables, comparing young people in out-of-home care with those not-in-care. The in-care group reported lower aspirations for themselves, saw their parents as having lower aspirations for them, received less support from parents with their studies, and reported less school stability. These results are consistent with other studies that have found lower levels of educational attainment and participation for children in care (Cashmore, et al., 2007; Trout, Hagaman, Casey, Reid, \& Epstein, 2008). Raising educational aspirations is crucial, so as to provide students with a reason to invest time and effort in learning and achieving, and cultivate cognitive engagement. The interviews suggested having a specific end-goal of education in mind assisted several of the participants to feel a sense of purpose and connection with their school environment. They had a vision or career goal, which appropriate guidance had made more tangible and accessible by breaking it down into achievable steps. This appeared to empower these young people to have a sense of 
control and direction for their studies. Learning and achieving at school had a pragmatic purpose. Young people’s personal motivation and tenacity also affected their level of school engagement. Going beyond the low expectations of parents provided a motivation for some participants, who spoke about their drive to create a different future and life for themselves from that of their own parents. This determination made them more willing to apply themselves at school. Recognition that young people's own motives and determination can be fundamental to their connectedness, underscores the importance of exploring life goals and motivations with young people, and ensures case planning is future-oriented. These aspirations could be many and varied, but if made explicit, discussed, and encouraged, may contribute to heightening young people’s own answers to questions such as, "Why bother to stay at school?”.

While the in-care group reported more school engagement than their not-in-care peers, there were different factors driving engagement for both groups. Aside from school achievement, for the in-care group, support from carers and support from their caseworker were the factors that most strongly predicted school engagement. For the comparison group, academic achievement, parental support, and friends who like school were more strongly associated with school engagement. This highlights the vital role of care system personnel, reinforcing that education cannot be left to schools (Jackson \& Cameron, 2012). We have previously discussed the role and responsibility of the carer and the caseworker in promoting education as a route to a better quality of life (Crawford, Tilbury, Creed \& Buys, 2011). Other studies have highlighted the role of the teacher (Driscoll, 2011; Gilligan, 1998; Harker et al., 2004; Martin \& Jackson, 2002; Merdinger et al., 2005). While many young people who were interviewed appreciated teachers who would take the time to assist and encourage them, be approachable, and have a relaxed and 
cheerful disposition, it seemed that teachers were not as vital to school engagement as carers and caseworkers.

Friends were not associated with school engagement to the same level as for young people not-in-care, possibly because moving schools more frequently means friends are not so influential. The desirability of reducing the number of school changes for young people during their in-care journey have been noted in other studies (Ferguson \& Wolkow, 2012). As some participants discussed, changing schools did adversely affect them. They missed out on learning particular academic concepts, which for some resulted in them being ill-prepared for their senior studies. Although staying at the same school may not always be possible, and the views of the young person must be taken into account, aiming to keep school stable should be an objective when placement transitions occur. This is relevant not only to educational goals, but to the capacity of children to make and keep school friends and enjoy their time at school.

Feeling successful within the school environment, whether this is with academic achievement or just managing the demands of schooling, also contributed to school connectedness. These young people spoke with pride about a number of their achievements, which contributed to their sense of self-esteem and competence. School was a place where they were good at something, and recognition of this had occurred. This, in part, contributed to engaging these young people emotionally, as the school environment evoked feelings of positivity, enjoyment, and success. The stability and safety dimension of school also seemed to contribute to young people’s emotional engagement. When school was seen as predictable and constant, they felt a part of a community that gave them a sense of belonging and connectedness. As noted by others (Gilligan, 1998; Zetlin et al., 2004) school can offer a number of emotional 
and psychological benefits, which for in-care children maybe particularly beneficial. Clearly, if the school environment is positive for young people, every effort should be made by caseworkers to maintain this important connection.

A few of the young people in this study also highlighted that, if learning materials and curricula were not appropriately leveled, this could lead to disengagement. Likewise for some, the actual school environment and requirements appeared incompatible for them. These issues emphasise the importance of timely, individualised assessments of young people’s educational needs, which includes learning materials and setting. Although there is diversity within the incare population regarding education needs, some alternative modes may be beneficial and warrant consideration.

School engagement is not static and can be cultivated, as "Routes to student engagement may be social or academic and may stem from opportunities in the school or classroom for participation, interpersonal relationships, and intellectual endeavours” (Fredricks et al., 2004, p. 61). Educational support plans are a formalised mechanism to identify and discuss a young person's educational goals and aspirations, and identify what support and assistance may be required to maximize educational success. Young people themselves are meant to be involved in the development of their plan as it represents a potential mechanism to increase engagement. It provides a means for students to set education-related goals and gain support (e.g., behaviour management plans for the classroom or playground, tutoring, learning aids). A few of the young people were aware of their education plan, and knew that they received support by way of resources, equipment, or tutoring. However, most of the young people were not aware of, or lacked detail on, what was contained within their own educational support plan, suggesting an 
opportunity to develop school engagement had been missed. For example, if a young person does not appear to be emotionally engaged at school, this could be explored with them, in terms of which teachers they like and what possible additional support, mentoring, and encouragement could be sourced for them. Likewise, if a young person has a particular career or job goal, their cognitive and behavioural engagement could be boosted by creating a clear pathway, with support for the young person. These initiatives could then be reviewed as part of planning. Yuen et al. (2012) identified in their study of Chinese adolescents' views on school connectedness that a variety of influences can promote a feeling of connectedness, such as positive and caring teachers, good relationships with friends and other personnel within the school, opportunities to progress talents and aspirations, quality guidance and counselling, and the use of non-harsh and consistent behaviour management approaches. However, education plans must be meaningful and actively involve young people and other relevant stakeholders (Hayden, 2005).

Consideration of the different elements of engagement along with appropriate and tailored academic support for young people may provide an additional mechanism for addressing the educational risks that children in out-of-home care may face.

\section{Conclusion}

Overall, the findings from this study suggest that it would be beneficial to give explicit attention to the cognitive, behavioural, and emotional dimensions of school engagement for children and young people in care. This could involve regular and purposeful conversations with children about their perceptions of school and their motives and aspirations. It would be valuable to ascertain for each young person what their educational "hook" is, as this could then allow for focused attention on establishing and maintaining this incentive. Considering the results from 
both the survey and the interviews, the following factors are suggested as important for increasing school engagement for children in care:

Behavioural

- Creating opportunities for successes (of all types) within the school environment

- Appropriate management of peer difficulties, such as bullying and teasing

- Inclusive, non-punitive responses to externalizing behaviours of students who have been maltreated as children

Emotional

- Recognising school as a venue for providing stability, safety, and enjoyment

- Attending to social skills so that children can develop friendships at school

- Expanding horizons, raising education and work aspirations

- Carer support for studies

- Children's caseworker involvement and assistance with education

- Support from teachers and other school staff

Cognitive

- Remedial assistance for young people who have fallen behind in learning

- Clear pathways, and assistance to map pathways, towards education and employment goals

- Recognising and cultivating the personal motivation and tenacity of young people

- School curricula tailored to the particular level and learning needs of young people 
Strategies for boosting the school engagement of young people in care may prove beneficial to interrupting and preventing the educational trajectories of disengagement and low academic attainment. Every effort should be given to keeping young people at school, so they have the opportunity to enjoy the social and intellectual rewards that positive schooling experiences can offer. Making a connection for young people at school promises to deliver a satisfying school experience that provides life-long returns. 


\section{References}

Allen, B., \& Vacca, J. S. (2010). Frequent moving has a negative effect on the school achievement of foster children makes the case for reform. Children and Youth Services Review, 32, 829-832. doi:10.1016/j.childyouth.2010.02.001

Altshuler, S.J. (2003). From barriers to successful collaboration: Public schools and child welfare working together. Social Work, 48, 52-63.

Berlin, M., Vinnerljung, B., \& Hjern, A. (2011). School performance in primary school and psychosocial problems in young adulthood among care leavers from long term foster care. Children and Youth Services Review, 33, 2489-2497.

Berridge, D. (2012). Educating young people in care: What have we learned? Children and Youth Services Review, 34, 1171-1175.

Cashmore, J., Paxman, M. \& Townsend, M. (2007) The educational outcomes of young people 4-5 years after leaving care: an Australian perspective. Adoption and Fostering, 31,5060.

Crawford, M., Tilbury, C., Creed, P. A., \& Buys, N. (2011). The role of carers and caseworkers in the school-to-work transition of young people in care. Australian Social Work, 64, 459-474. doi:10.1080/0312407X.2010.537353

Creed, P. A., Tilbury, C., Buys, N., \& Crawford, M. (2011). The career aspirations and action behaviours of Australian adolescents in out-of-home-care. Children and Youth Services Review, 33, 1720-1729. 
Dill, K., Flynn, R.J., Hollingshead, M., \& Fernandes, A. (2012). Improving the educational achievement of young people in out-of-home care. Children and Youth Services Review, 34, 1081-1083.

Downey, L (2007). Calmer Classrooms. Melbourne, Australia: Child Safety Commissioner. Retrieved from Child Safety Commissioner website: http://www.kids.vic.gov.au/downloads/calmer_classrooms.pdf

Driscoll, J. (2011). Making up lost ground: Challenges in supporting educational attainment of looked after children beyond Key Stage 4. Adoption \& Fostering, 35(2), 18-30.

Dworsky, A. (2010). Does Extending Foster Care Beyond Age 18 Promote Postsecondary Educational Attainment? Chapin Hall Issue Brief, March, Chicago: Chapin Hall Center for Children.

Elliott, A. (2002). The educational expectation of looked after children. Adoption \& Fostering, 26(3), 58-68.

Farruggia, S. P., Greenberger, E., Chen, C., \& Heckhausen, J. (2006). Perceived social environment and adolescents' well-being and adjustment: Comparing a foster care sample with a matched sample. Journal of Youth and Adolescence, 35, 349-358.

Ferguson, H.B. \& Wolkow, K. (2012). Educating children and youth in care: A review of barriers to school progress and strategies for change. Children and Youth Services Review, 34, 1143-1149.

Finlay, K.A., \& National Center for School Engagement. (2006), Quantifying School Engagement: Research Report. Retrieved from National Center for School Engagement website: 
http://www.schoolengagement.org/TruancypreventionRegistry/Admin/Resources/Resour ces/111.pdf

Flynn, R.J., Paquet M., \& Marquis, R.A. (2010). Can tutoring by foster parents improve foster children’s basic academic skills. In: How does foster care work? (eds. E. Fernandez, E. \& R.P. Barth), pp. 260-273. London: Jessica Kingsley Publishers.

Forsman, H., \& Vinnerljung, B. (2012). Interventions aiming to improve school achievements of children in out-of-home care: A scoping review. Children and Youth Services Review, 34, 1084-1091.

Frederick, J., \& Goddard, C. (2010). ‘School was just a nightmare’: childhood abuse and neglect and school experiences. Child and Family Social Work, 15, 22-30.

Fredricks, J.A., Blumenfeld, P.C., \& Paris, A.H. (2004). School engagement: Potential of the concept, state of the evidence. Review of Educational Research, 74(1), 59-109.

Gilligan, R. (1998). The importance of schools and teachers in child welfare. Child and Family Social Work, 3, 13-25.

Harker, R.M., Dobel-Ober, D., Akhurst, S., Berridge, D., \& Sinclair, R. (2004). Who takes care of education 18 months on? A follow-up study of looked after children's perceptions of support for educational progress. Child and Family Social Work, 9, 273-284.

Hayden, C. (2005). More than a piece of paper? Personal education plans and 'looked after' children in England. Child and Family Social Work, 10, 343-352.

Iversen, A.C., Hetland, H., Havik, T., \& Stormark, K.M. (2010). Learning difficulties and academic competence among children in contact with the child welfare system. Child and Family Social Work, 15, 307-314. 
Jackson, S. and Cameron, C. (2012) Leaving care: Looking ahead and aiming higher. Children and Youth Services Review, 34, 1107-1114

Kirk, R., \& Day, A. (2011). Increasing access for youth aging out of foster care: Evaluation of a summer camp program for foster youth transitioning from high school to college. Children and Youth Services Review, 33, 1173-1180.

Labaree, D.F. (1997). Public goods, private goods: The American struggle over educational goals. American Educational Research Journal, 34(1), 39-81.

Libbey, H.P. (2004). Measuring Student Relationships to School: Attachment, Bonding, Connectedness, and Engagement. Journal of School Health, 74, 274-283.

Martin, P.Y., \& Jackson, S. (2002). Educational success for children in public care: advice from a group of higher achievers. Child and Family Social Work, 7, 121-130.

Merdinger, J.M., Hines, A.M., Osterling, K.L., \& Wyatt, P. (2005) Pathways to college for former foster youth: Understanding factors that contribute to educational success. Child Welfare, 84, 867-895.

O’Sullivan, A., \& Westerman, R. (2007). Closing the gap. Investigating the barriers to educational achievement for looked after children. Adoption \& Fostering, 31(1), 13-19.

Stone, S. (2007). Child maltreatment, out-of-home placement and academic vulnerability: A fifteen-year review of evidence and future directions. Children and Youth Services Review, 29, 139-161.

Trout, A.L., Hagaman, J., Casey, K., Reid, R., \& Epstein, M.H. (2008). The academic status of children and youth in out-of-home care: A review of the literature. Children and Youth Services Review, 30, 979-994. 
Wise, S., Pollock, S., Mitchell, G., Argus, C., \& Farquhar, P. (2010). Care System Impacts on Academic Outcomes: Research Report. Melbourne: Anglicare Victoria and Wesley Mission Victoria. Retrieved from Anglicare website: http://www.anglicarevic.org.au/index.php?action=filemanager\&doc_form_name=downlo ad\&folder_id=806\&doc_id=8837

Working Group on Education for Children and Young People in Out-of-Home Care in Queensland (2011). Education Matters. Brisbane, Australia: Retrieved from Edmund Rice Education website: http://www.ereflc.org.au/docs/EducationMattersReport.pdf Yuen, M., Lau, P.S.Y., Lee, Q.A.Y., Gysbers, N.C., Chan, R.M.C., Fong, R.W., Chung, Y.B., \& Shea, P.M.K. (2012). Factors influencing school connectedness: Chinese adolescents’ perspectives. Asia Pacific Education Review, 13(1), 55-63.

Zetlin, A.G. \& Weinberg, L.A. (2004). Understanding the plight of foster youth and improving their educational opportunities. Child Abuse and Neglect, 28, 917-923.

Zetlin, A., Weinberg, L., \& Kimm, C. (2004) Improving education outcomes for children in foster care: Intervention by and education liaison. Journal of Education for Students Placed at Risk, 9, 421-429. 
Table 1

Descriptive Statistics

\begin{tabular}{lrrrrrrr}
\hline & \multicolumn{3}{c}{ In-care } & \multicolumn{5}{c}{ Not-in-care } \\
\cline { 2 - 8 } Variable & $N^{\#}$ & $M$ & $S D$ & $N$ & $M$ & $S D$ \\
\hline School engagement & 202 & 37.59 & 8.77 & 202 & 35.78 & $8.21^{*}$ \\
School aspirations: Self & 195 & 5.20 & 1.93 & 202 & 6.08 & $1.17^{*}$ \\
School aspirations: Parents & 189 & 5.37 & 1.71 & 198 & 6.02 & $1.18^{*}$ \\
School stability & 202 & 1.34 & .60 & 202 & 1.09 & $.33^{*}$ \\
Parent support for studies & 202 & 2.25 & 1.08 & 202 & 2.94 & $.86^{*}$ \\
Number of friends & 199 & 2.79 & .52 & 198 & 2.86 & .45 \\
Friends who like school & 199 & 2.38 & .89 & 201 & 2.41 & .83 \\
Friends who intend to finish Yr 12 & 195 & 2.74 & .88 & 199 & 2.88 & .81 \\
& & & & & & \\
\hline
\end{tabular}

\# Not all students answered all questions. * Indicates significant difference between the two groups; $p<.001$. 
Table 3

Predicting School Engagement

\begin{tabular}{|c|c|c|c|c|c|c|}
\hline \multirow[b]{2}{*}{ Variables } & \multicolumn{3}{|l|}{ In-care } & \multicolumn{3}{|c|}{ Not-in-care } \\
\hline & $B$ & SEB & $\beta$ & $B$ & SEB & $\beta$ \\
\hline \multicolumn{7}{|l|}{ Step 1} \\
\hline School achievement & 2.33 & .79 & $.22 * *$ & 3.55 & .70 & $.34 * * *$ \\
\hline \multicolumn{7}{|l|}{ Step 2} \\
\hline School achievement & 1.89 & .78 & $.18^{*}$ & 2.07 & .70 & $.20 * *$ \\
\hline School aspirations: Parents & .20 & .38 & .04 & & & \\
\hline School stability & -.65 & .99 & -.05 & & & \\
\hline Parent support with studies & 1.28 & .55 & $.16^{*}$ & 2.60 & .63 & $.27 * * *$ \\
\hline Friends who like school & 1.64 & .80 & $.17^{*}$ & 1.89 & .65 & $.19 * *$ \\
\hline Friends to finish Yr 12 & 1.48 & .83 & .15 & 1.11 & .69 & .11 \\
\hline Family at college & -3.02 & 1.21 & $-.17^{*}$ & & & \\
\hline School aspirations: Self & & & & .35 & .48 & .05 \\
\hline \multicolumn{7}{|l|}{ Step 3} \\
\hline School achievement & 2.07 & .75 & $.19 * *$ & & & \\
\hline School aspirations: Parents & .18 & .37 & .03 & & & \\
\hline School stability & -.73 & .96 & -.05 & & & \\
\hline Parent support with studies & .47 & .56 & .06 & & & \\
\hline Friends who like school & 1.22 & .77 & .12 & & & \\
\hline Friends to finish Yr 12 & 1.34 & .79 & .13 & & & \\
\hline Family at college & -3.02 & 1.15 & $-.17 * *$ & & & \\
\hline Carer support with studies & 1.98 & .60 & $.23^{* *}$ & & & \\
\hline Caseworker helpfulness & 1.40 & .53 & $.18^{* *}$ & & & \\
\hline
\end{tabular}


Table 2

Bivariate Correlations: In-care Group above the Diagonal $(N=202) ;$ Not-in-care Group below the Diagonal $(N=202)$

\begin{tabular}{|c|c|c|c|c|c|c|c|c|c|c|c|c|c|c|c|c|c|c|c|c|}
\hline & 1 & 2 & 3 & 4 & 5 & 6 & 7 & 8 & 9 & 10 & 11 & 12 & 13 & 14 & 15 & 16 & 17 & 18 & 19 & 20 \\
\hline 1. School engagement & 1 & .07 & $.16^{*}$ & $-.15^{*}$ & $.17 *$ & .07 & $.33 * *$ & $.30 * *$ & .03 & $-.18 *$ & .03 & .08 & -.04 & $.37 * *$ & .14 & -.01 & $.22 * *$ & -.11 & .00 & $.20 * *$ \\
\hline 2. School aspirations: Self & $.25 * *$ & 1 & $.47 * *$ & $-.25 * *$ & .05 & $.18^{*}$ & $.19 * *$ & $.27 * *$ & .12 & -.01 & $.47 * *$ & -.04 & .00 & .06 & .02 & .02 & .01 & -.04 & -.14 & $.27 * *$ \\
\hline 3. School aspirations: Parents & .12 & $.68 * *$ & 1 & -.11 & $.15^{*}$ & .07 & .14 & $.29 * *$ & $.26 * *$ & .14 & $.68^{* *}$ & -.03 & .00 & .09 & .01 & .04 & .02 & .07 & .04 & $.25 * *$ \\
\hline 4. School stability & -.03 & -.02 & .09 & 1 & -.09 & -.03 & $-.18^{*}$ & $-.22 * *$ & .03 & .02 & -.05 & -.06 & -.03 & -.13 & $-.26 * *$ & $-.19 * *$ & .05 & $.37 * *$ & -.07 & .11 \\
\hline 5. Parent support with studies & $.38 * *$ & $.26 * *$ & $.24 * *$ & .04 & 1 & -.03 & $.14^{*}$ & .09 & $.18^{* *}$ & .08 & .04 & -.03 & -.12 & $.29 * *$ & .08 & -.09 & $.20 * *$ & -.12 & .08 & -.00 \\
\hline 6. No. friends & .09 & $.14^{*}$ & .14 & -.02 & $.20 * *$ & 1 & $.21 * *$ & $.24 * *$ & $.17 *$ & .03 & $.22 * *$ & .06 & -.07 & .11 & .02 & -.13 & .12 & -.00 & -.10 & .13 \\
\hline 7. Friends who like school & $.31^{* *}$ & .13 & .09 & .03 & $.19 * *$ & $.21 * *$ & 1 & $.56 * *$ & .12 & .01 & $.16^{*}$ & -.06 & $-.16^{*}$ & $.20 * *$ & .11 & -.01 & .10 & $-.22 * *$ & -.04 & $.22 * *$ \\
\hline 8. Friends to finish Yr 12 & $.27 * *$ & $.31 * *$ & $.25 * *$ & -.01 & $.16^{*}$ & .12 & $.26 * *$ & 1 & .07 & -.01 & $.27 * *$ & .05 & -.11 & .14 & $.15^{*}$ & .05 & .06 & -.04 & -.03 & $.18^{*}$ \\
\hline 9. Family at & .07 & $.21 * *$ & $.24^{* *}$ & .07 & .04 & $.16^{*}$ & $.20 * *$ & $.21 * *$ & 1 & $.34^{* *}$ & $.18^{*}$ & $-.25^{* *}$ & $-.15^{*}$ & .10 & .09 & .00 & .07 & .05 & -.00 & $.25^{* *}$ \\
\hline 10. Fan & -.02 & .01 & .09 & .01 & -.01 & .02 & .01 & -.05 & $.18^{* *}$ & 1 & .06 & -.14 & $-.27 * *$ & .02 & -.02 & .12 & -.01 & .05 & .07 & .10 \\
\hline 11. Scho & - & - & - & - & - & - & - & - & - & - & 1 & -.06 & .02 & .11 & -.01 & -.04 & .04 & .06 & -.12 & $.23^{* *}$ \\
\hline 12. Carers at & - & - & - & - & - & - & - & - & - & - & - & 1 & $.34 * *$ & .08 & -.01 & .14 & -.14 & -.05 & .00 & -.12 \\
\hline 13. Care & - & - & - & - & - & - & - & - & - & - & - & - & 1 & $-.18 *$ & -.01 & .05 & $-.18 *$ & .03 & -.08 & .05 \\
\hline rt with studies & - & - & - & - & - & - & - & - & - & - & - & - & 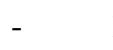 & 1 & $.23 * *$ & .03 & $.19 * *$ & $-.16^{*}$ & .03 & -.02 \\
\hline 15. Time & - & - & - & - & - & - & - & - & - & - & - & - & - & - & 1 & $.26 * *$ & -.01 & .08 & -.13 & -.01 \\
\hline 16. Cont & - & - & - & - & - & - & - & - & - & - & - & - & - & - & - & 1 & $-.49 * *$ & .08 & -.13 & -.01 \\
\hline 17. Caseworker helpfulness & - & - & - & - & - & - & - & - & - & - & - & - & - & - & - & - & 1 & -.08 & .14 & -.04 \\
\hline 18. Age & -.05 & .1 & .12 & -.01 & $-.19 * *$ & .02 & .01 & $.25 * *$ & .06 & .09 & - & - & - & - & - & - & - & 1 & -.08 & .10 \\
\hline 19. Genc & .00 & $-.14 *$ & -.09 & .03 & -.09 & .02 & -.05 & -.14 & .02 & .10 & - & - & - & - & - & - & - & -.09 & 1 & $-.14^{*}$ \\
\hline 20. School achievement & $.34 * *$ & $.33 * *$ & $.24 * *$ & -.05 & $.21 * *$ & .10 & $.20 * *$ & $.27 * *$ & $.17 *$ & .11 & - & - & - & - & - & - & - & -.03 & .03 & 1 \\
\hline
\end{tabular}

$* p<.05, * * p<.01$ 
